\title{
Los derechos humanos y el desarrollo social integral en los Estados: una perspectiva frente a la paz, la economía y el gobierno?'.
}

\author{
Human rights and comprehensive social development in States: a perspective \\ on peace, the economy and the government \\ Katerin Yulieth Cruz Cadena ${ }^{2}$ \\ Sergio Andrés Caballero Palomino ${ }^{3}$ \\ Daniel Fabián Torres Bayona ${ }^{4}$ \\ RESUMEN
}

El presente artículo pretende realizar una revisión jurídica para responder ¿cuál es la relación de los derechos humanos y el desarrollo integral de los Estados frente a la paz, la economía y el gobierno en Colombia?; como estrategia metodológica posee un enfoque jurídico; utilizando el tipo de investigación descriptivo y correlacional; implementando los métodos de investigación deductivo, de análisis y de síntesis; teniendo como fuentes primarias el derecho internacional,

\footnotetext{
1Artículo derivado de un trabajo de investigación desarrollado a partir algunas aportaciones reflexivas y revisiones sobre el tema.

2 Especialista en Derecho Penal y Criminología, Universidad Libre Seccional Barranquilla. Abogada, Universidad del Atlántico. Estudiante de Psicología, Universidad Cooperativa de Colombia. Gerente General y Profesora del Colectivo Nacional de Abogados. E-mail: Abg.katerincruz@hotmail.com

3 Maestrando en Derecho del Estado con énfasis en Derecho Público, Universidad Externado de Colombia. Especialista en Derecho Administrativo, Universidad Libre Seccional Barranquilla. Abogado, Universidad Libre Seccional Socorro. Profesor e Investigador, Corporación Universitaria de Ciencia y Desarrollo, UNICIENCIA, Bogotá. E-mail: abogadosergiocaballero@hotmail.com.

4 Doctorando en Derecho, Universitat Autònoma de Barcelona. Magíster en Derecho con énfasis en Derecho Público, Universidad Externado de Colombia. Especialista en Derecho Público, Universidad Autónoma de Bucaramanga. Abogado, Universidad Industrial de Santander. E-mail: dtorresbayona@gmail.com
}

Recibido: 29 de septiembre de 2018

Aprobado: 24 de Noviembre de 2018. 
la Constitución, la ley y la jurisprudencia de Colombia, y como fuente secundaria la doctrina; como técnica de investigación se utilizó el análisis de contenido de texto.

\title{
Palabras claves:
}

Derechos humanos, desarrollo social integral, dignidad humana, paz, economía, gobierno.

\begin{abstract}
This article intends to carry out a legal review to answer what is the relationship of human rights and the integral development of States in the face of peace, economy and government in Colombia ?; as a methodological strategy it has a legal focus; using the descriptive and correlational type of research; implementing deductive research, analysis and synthesis methods; having as primary sources international law, the Constitution, the law and jurisprudence of Colombia, and doctrine as a secondary source; as a research technique the analysis of text content.
\end{abstract}

\section{Keywords:}

Human rights, integral social development, human dignity, peace, economy, government. 


\section{Introducción}

En el marco del nuevo derecho constitucional para la paz que surge del Acuerdo del Teatro Colón suscrito entre el Gobierno Nacional y la insurgencia en noviembre de 2016 y refrendado por el Congreso de la República en diciembre del mismo año, surge la pregunta sobre cuál es la relación que existen entre los derechos humanos y el desarrollo social integral en los Estados.

Para ello, este artículo pretende aportar a la discusión desde las perspectivas de la paz, la economía y el gobierno, poniendo énfasis en la dignidad humana, los derechos de las víctimas a la verdad, la justicia y la reparación integral, todo ello desde la perspectiva de la justicia transicional que ha entrado a operar a trasvés de la Jurisdicción Especial para la Paz, como componente imprescindible del Sistema de Verdad, Justicia, Reparación y No Repetición.

\section{Discusión y desarrollo del tema: La dignidad Humana como eje central para el desarrollo integral en clave de derechos humanos.}

La dignidad humana se constituye el eje central del Estado Social de Derecho en Colombia, es por eso que desde el artículo 1 de la Constitución se indica que "Colombia es un Estado Social de Derecho fundado en el respecto de la dignidad humana", por tanto el Estado debe realizar todas sus actuaciones y toma de decisiones de acuerdo a la protección de la persona y del respeto de la dignidad humana con relación al ejercicio de los demás derechos fundamentales en el cual se desarrolla el individuo en la vida social, al respecto la Corte Constitucional en Sentencia SU-062 de 1999 ha indicado: 
(...) la dignidad se erige como un derecho fundamental, de eficacia directa, cuyo reconocimiento general compromete el fundamento político del Estado colombiano. Desarrollando los conceptos anteriores, la jurisprudencia constitucional en torno del derecho a la vida ha hecho énfasis en que éste no hace relación exclusivamente a la vida biológica, sino que abarca también las condiciones de vida correspondientes a la dignidad intrínseca del ser humano. Ha tratado entonces del derecho a la vida digna, y se ha referido al sustrato mínimo de condiciones materiales de existencia, acordes con el merecimiento humano, llamándolo mínimo vital de subsistencia. (Sentencia SU-062, 1999)

Así las cosas, es importante señalar que en Colombia la razón de ser del Estado es la persona y en especial su dignidad humana de donde se derivan todos los demás derechos para que tenga una vida con el mínimo de condiciones para vivir y desarrollarse como ser. La conceptualización de Derechos Humanos desde la óptica de NIKKEN (1994, p. 15) ilustra al respecto "La noción de derechos humanos se corresponde con la afirmación de la dignidad de la persona frente al Estado", y continúa indicando que "El poder público debe ejercerse al servicio del ser humano: no puede ser empleado lícitamente para ofender atributos inherentes a la persona y debe ser vehículo para que ella pueda vivir en sociedad en condiciones cónsonas con la misma dignidad que le es consustancial."(NIKKEN, 1994, p. 15). En concordancia de lo anterior, en el texto denominado los derechos humanos y la reducción de la pobreza: Un marco conceptual, se trata el tema de la pobreza relacionado con los derechos Humanos se lee:

La razón por la que la concepción de la pobreza está relacionada con libertades básicas es que éstas se reconocen como fundamentalmente valiosas para lograr una unidad humana mínima. Ahora bien, la preocupación por la dignidad humana motiva asimismo el enfoque de los derechos humanos, que postula que el ser humano tiene derechos inalienables a esas libertades. Si alguien no ha podido adquirir esas libertades, obviamente sus derechos a esas libertades no se han realizado. 
Por consiguiente, la pobreza se puede definir de manera equivalente bien como la falta de libertades básicas - desde la perspectiva de las capacidades -, o bien como la no realización de los derechos a esas libertades - desde la perspectiva de los derechos humanos (OACDH, 2004, pág. 10)

Los derechos humanos, al ser esos postulados que dignifican a la persona en el desarrollo de sus actividades de la vida en sociedad frente a la educación, el trabajo, su posición y participación dentro de un determinado gobierno, la economía, la salud, la seguridad social, la protección a las garantías del ser humano y la paz se convierten en una herramienta para el crecimiento y desarrollo de los Estados y especialmente de las personas, las cuales son el principal y único objeto. Es importante acudir a la Carta de las Naciones Unidas, firmada en San Francisco el 26 de junio de 1945, para mostrar históricamente la preocupación y el lazo intimo que existe entre los derechos humanos en la órbita internacional frente a la paz, la justicia, la economía, entre otros aspectos, para esto es preciso acudir a su capítulo primero, artículo 1, el cual menciona los propósitos de las Naciones Unidas: "Mantener la paz y la seguridad internacionales, y con tal fin: tomar medidas colectivas eficaces para prevenir y eliminar amenazas a la paz, y para suprimir actos de agresión u otros quebrantamientos de la paz; y lograr por medios pacíficos, y de conformidad con los principios de la justicia y del derecho internacional, el ajuste 0 arreglo de controversias o situaciones internacionales susceptibles de conducir a quebrantamientos de la paz" (Organización de Naciones Unidas, 1945), y dentro del artículo mencionado, en su numeral 3 señala "Realizar la cooperación internacional en la solución de problemas internacionales de carácter económico, social, cultural o humanitario, y en el desarrollo y estímulo del respeto a los derechos humanos y a las libertades fundamentales de todos, sin hacer distinción por motivos de raza, sexo, idioma o religión;". Más adelante, en 1948, con la expedición de la Declaración Universal de los Derechos Humanos, el primer párrafo de la mencionada, establece "Considerando que la libertad, la justicia y la paz en el mundo tienen por base el reconocimiento de la dignidad intrínseca y de los derechos iguales e inalienables de todos los miembros de la familia humana" (Declaración Universal de los Derechos Humanos, 1948). 


\section{Desarrollo social y derechos humanos.}

Frente al desarrollo social, es de gran importancia acudir a la denominada Declaración sobre el Derecho al Desarrollo, adoptada por la Asamblea General de las Naciones Unidas mediante Resolución Número 41/128 del 04 de diciembre de 1986, en el cual en su preámbulo reconoce los postulados de la Carta de Naciones Unidas; reconoce también el desarrollo global en el ámbito económico, social, cultural y político que apunta al mejoramiento de los pueblos y de las personas encaminados al desarrollo y distribución justa de beneficios; además reconoce que la paz y la seguridad internacional son elementos indispensable al derecho al desarrollo. El derecho al desarrollo está definido por el artículo 1 de dicha Declaración en los siguientes términos:

"El derecho al desarrollo es un derecho humano inalienable en virtud del cual todo ser humano y todos los pueblos están facultados para participar en un desarrollo económico, social, cultural y político en el que puedan realizarse plenamente todos los derechos humanos y libertades fundamentales, a contribuir a ese desarrollo y a disfrutar del él. 2. El derecho humano al desarrollo implica también la plena realización del derecho de los pueblos a la libre determinación, que incluye, con sujeción a las disposiciones pertinentes de ambos Pactos internacionales de derechos humanos, hombres y mujeres ( Almanaza, Carpintero y mercado, 2018), en el ejercicio de su derecho inalienable a la plena soberanía sobre todas sus riquezas y recursos naturales." (Asamblea General de Naciones Unidas, 1986).

De esta Declaración además es importante resaltar el artículo 2:

1. La persona humana es el sujeto central del desarrollo y debe ser el participante activo y el beneficiario del derecho al desarrollo.

2. Todos los seres humanos tienen, individual y colectivamente, la responsabilidad del desarrollo, teniendo en cuenta la necesidad del pleno respeto de sus derechos 
humanos y libertades fundamentales, así como sus deberes para con la comunidad, único ámbito en que se puede asegurar la libre y plena realización del ser humano, y, por consiguiente, deben promover y proteger un orden político, social y económico apropiado para el desarrollo.

3. Los Estados tienen el derecho y el deber de formular políticas de desarrollo nacional adecuadas con el fin de mejorar constantemente el bienestar de la población entera y de todos los individuos sobre la base de su participación activa, libre y significativa en el desarrollo y en la equitativa distribución de los beneficios resultantes de éste. (Asamblea General de Naciones Unidas, 1986)

Dese la óptica internacional, se le ha dado gran importancia al desarrollo, el cual está inmerso en ámbitos como la paz, la economía, la gobernabilidad (Buelvas y Florez, 2017), la política y en general todas aquellos aspectos de la vida en sociedad que permiten el engrandecimiento del ser humano en su dignidad, en su vida, en sus derechos y garantías, en este orden de ideas, es importante entender que los Derechos Humanos constituyen un vehículo en el crecimiento y desarrollo social de los Estados y del ser humano que es su objeto principal.

En Colombia puede observarse un ejemplo claro de la influencia de los derechos humanos en la paz, en la economía, en la gobernabilidad y en el desarrollo social, con la Ley de víctimas, que corresponde a la Ley 1448 de 2011; esta norma está dirigida a las víctimas del conflicto interno armado y tiene relación con la paz porque marca la pauta de la justicia transicional, la verdad y la reparación integral; frente a la economía, gobernabilidad y desarrollo social también se encuentran medidas dirigidas hacia este grupo vulnerable como es el caso de la ayuda humanitaria, los planes y proyectos encaminados a las víctimas, la restitución de tierras, las medidas de satisfacción ya sean de manera económica, simbólica o de enfoque diferencial, este último quiere decir que se les da prelación y mayores garantías a las personas que tengan el reconocimiento de víctimas. 
El carácter de las medidas transicionales se encuentra en el artículo 9 de la Ley 1448 de 2011 que al tenor literal dice:

El Estado reconoce que todo individuo que sea considerado víctima en los términos en la presente ley, tiene derecho a la verdad, justicia, reparación y a que las violaciones de que trata el artículo $3^{\circ}$ de la presente ley, no se vuelvan a repetir, con independencia de quién sea el responsable de los delitos.

Las medidas de atención, asistencia y reparación adoptadas por el Estado, tendrán la finalidad de contribuir a que las víctimas sobrelleven su sufrimiento y, en la medida de lo posible, al restablecimiento de los derechos que les han sido vulnerados. Estas medidas se entenderán como herramientas transicionales para responder y superar las violaciones contempladas en el artículo $3^{\circ}$ de la presente Ley.

\section{$(\ldots)$}

En el marco de la justicia transicional las autoridades judiciales y administrativas competentes ( Pérez,2015) deberán ajustar sus actuaciones al objetivo primordial de conseguir la reconciliación y la paz duradera y estable. Para estos efectos se deberá tener en cuenta la sostenibilidad fiscal, la magnitud de las consecuencias de las violaciones de que trata el artículo $3^{\circ}$ de la presente Ley, y la naturaleza de las mismas (Congreso de la República de Colombia, 2011)

Frente a la justicia transicional, Rodrigo UPRIMNY YEPES, Catalina BOTERO MARINO, Esteban RESTREPO \& María Paula SAFFON, en el texto titulado ¿Justicia transicional sin transición? Reflexiones sobre verdad, justicia y reparación en Colombia, tratan el tema del dilema de la justicia transicional:

Los procesos de justicia transicional buscan, ordinariamente, llevar a cabo una transformación radical del orden social y político de un país, o bien para reemplazar un estado de guerra civil por un orden social pacífico, o bien para pasar de una dictadura a un orden político democrático. Especialmente cuando se trata de transiciones cuyo 
objetivo es dejar atrás un conflicto armado y reconstituir el tejido social, dicha transformación implica la difícil tarea de lograr un equilibrio entre las exigencias de justicia y paz, es decir, entre los derechos de las víctimas del conflicto y las condiciones impuestas por los actores armados para desmovilizarse. $Y$ es que existen tensiones entre las exigencias jurídicas internacionales relativas a los derechos a la verdad, la justicia y la reparación de las víctimas de crímenes de guerra o de lesa humanidad, y las restricciones impuestas por las negociaciones de paz llevadas a cabo por los actores armados con miras a lograr la paz. Así, aun cuando la normatividad internacional ha hecho de la obligación de individualizar y sancionar a los responsables de graves violaciones de derechos humanos un imperativo cada vez más estricto, la imposición de sanciones de ese tipo en todos los casos puede obstaculizar e incluso llevar al fracaso a un acuerdo de paz.

Porque, hay que aceptarlo, en un contexto de guerra, ningún actor armado estaría dispuesto a participar en un acuerdo de paz que no representara ningún atractivo para él. (Uprimny, et.al., 2005)

\section{Conclusiones}

Como conclusión se puede observar que los Derechos Humanos siempre estarán encaminados al desarrollo de la sociedad y a la dignificación de la persona, en todos los aspectos de la vida comunitaria, elementos como el medio ambiente sano, la educación, la política, la economía y uno de los fines más perseguidos que corresponde a la paz.

En Colombia existen tensiones frente a la justicia transicional, pues dicho tema encierra los derechos a las víctimas, pero también se tiene en contraposición las condiciones que quieren imponer los grupos al margen de la ley y una de las cosas que no se puede 
permitir es la impunidad de dichos grupos armados, pero por otra parte si no se plantean acuerdos, la situación de violencia seguirá en nuestro país y se verán perjudicados todos los ámbitos sociales como la economía, la forma de gobernar y en general la vida de las personas, pues dicha justicia transicional y la ley de víctimas no servirán si se siguen generando perjuicios a la población civil y se convertirá en un desgaste estatal en el cual reparan a unas víctimas, pero luego se verán afectados al doble o más.

\section{Referencias.}

Almanza Iglesias, M., Carpintero Mercado, K., \& Mercado Villa, L. K. (2018). Estabilidad laboral de la mujer trabajadora en estado de embarazo. Erg@omnes, 10(1), 129-155. https://doi.org/10.22519/22157379.1216

Asamblea General de Naciones Unidas. (4 de Diciembre de 1986). Declaración sobre el derecho al desarrollo resolución 41/128.

Asamblea Nacional Constituyente . (1991). Constitución Política de Colombia .

Buelvas Mendoza, M., \& Florez Campo, O. (2017). Elementos para la discusión sobre la gobernanza y gobernabilidad en el posconflicto en Colombia. Erg@omnes, 9(1), 145-168. https://doi.org/10.22519/22157379.1016

Congreso de la República de Colombia. (2011). Ley 1448. Por la cual se dictan medidas de atención, asistencia y reparación integral a las víctimas del conflicto armado interno y se dictan otras disposiciones. 
Declaración Universal de los Derechos Humanos. (1948). París .

Nikken, P. (1994). EL CONCEPTO DE DERECHOS HUMANOS. Estudios Básicos de Derechos Humanos. San José .

OACDH. (2004). Los derechos humanos y la reducción de la pobreza: un marco conceptual. Nueva York y Ginebra: Naciones Unidas.

Organización de Naciones Unidas. (26 de Junio de 1945). Conferencia de las Naciones Unidas sobre Organización Internacional. Carta de las Naciones Unidas. San Francisco.

Pérez Vásquez, R. (2015). La decisión judicial. Erg@omnes, 7(1), 30-55. https://doi.org/10.22519/22157379.742

Sentencia SU-062 (Corte Constitucional de Colombia 1999).

Uprimny Yepes, R., Botero Marino, C., Esteban, R., \& Saffon, M. P. (2005). Rodrigo Uprimny Yepes, Catalina Botero Marino, Esteban Restrepo, \& María Paula Saffon. ¿Justicia transicional sin transición? Reflexiones sobre verdad, justicia y reparación en Colombia. Centro de Estudios de Derecho, Justicia y Sociedad (DJS). Bogotá, no. Bogotá: Centro de Estudios de Derecho, Justicia y Sociedad (DJS). 